\title{
9
}

\section{Co-decision within Cooperative Processes: Analysis, Design and Implementation Issues}

\author{
Giorgio De Michelis
}

Laboratory for Cooperation Technologies, Department of Information Sciences, University of Milano

Via Comelico 39, 20135 Milano, Italy; tel: +39255006 311; fax: + 39 255006 276; email: gdemich@hermes.dsi.unimi.it

and

RSO SpA

Via Leopardi 1, 20124 Milano, Italy

\begin{abstract}
This paper analyzes group decision making from a pragmatic point of view, as a sub-process of a cooperative process. It shows how group decision making is carried on through two different co-decision forms (namely co-decision with equal and distinct roles) depending on the positional relations of its participants. Since the position (client or performer) of a participant in a co-decision is highly context dependent, co-decision support systems must enhance the awareness of their users with respect to the cooperative process and the positional relation where they are situated.
\end{abstract}

\section{Keywords}

CSCW, DSS, GDSS, Co-Decision, Cooperative Process

\section{INTRODUCTION}

Decision Support Systems (DSS) appeared in the seventies as an evolutionary advancement beyond earlier philosophies of EDP and MIS (Keen, Scott Morton 1978; Sprague, Carlson, 1982). Rather than merely processing and delivering information on the basis of a previously defined schema, DSS are designed to actively interact with the decision maker, to assist her with information processing in arriving at better decisions.

The process of decision making (Simon, 1960) is made up of four major phases (Sprague, Carlson, 1982):

1. the intelligence phase, which consists in problem recognition and definition; 
2. the design phase, which encompasses the generation of (alternative) problem solutions;

3. the choice phase, which is characterized by the selection of an appropriate solution;

4. the implementation phase, which deals with justifying and executing the chosen solution.

The rationality of decision making processes depends therefore on the quality of the chosen solution with respect to possible alternatives, i.e. on the completeness of the space of possible solutions taken into account together with the adequacy of the criterion through which one solution is chosen with respect to the problem to be solved (Simon, 1960).

Most DSS are characterized by the fact that they support primarily individuals instead of groups, while almost all important managerial decisions are the results of group activity. Any individual decision by a member of a group (decisions are always made by individuals) is in fact a moment of the process through which the latter deliberates something defining and/or influencing the future behaviour of the group and the process under its responsibility. Boards, committees, teams, councils etc. are typical names of groups where decisions are taken.

The quality of the deliberation process of a group is not the sum of the qualities of the decisions of its members: any different member of the group may in fact define the problem in a different way either because she has different information or because she has different aims, and any therefore may choose a different solution. Moreover, since the final decision of the group is the result either of a combination of the individual decisions of its members or of the selection of one of them, it cannot be rational in the above sense (it cannot be the best combination or the best choice). The social dimension of the group decision process affects its rationality defining new requirements for the sytems supporting it, which are not taken into account by traditional DSS.

Ever since the late seventies, early eighties awareness of the fact that major organizational decisions are never taken by individuals in isolation has grown. This has brought forth the need for systems supporting the group where they are taken, its deliberating capability, rather than the rationality of its members' decisions. The focus has shifted therefore from the fourphase model of rational decision making (Sprague, Carlson, 1982) to other views of group decision making (Kraemer, King, 1986) enlightening its social nature (interest conflicts, influences, power relations, ...), its multiplicity (different views and different solutions foreseen by different actors, ...), its complexity (forthcoming problems and opportunities, changing contexts, ...).

New support systems have been conceived from this perspective, namely Group Decision Support System (GDSS - Kraemer, King, 1986; Lee et al., 1988), which, instead of supporting the rationality of the decision as in the case of DSS, provide support: for the communication between members of a group, in particular for contexts of direct contact like decision rooms (Dennis et al., 1987) and collaboration laboratories (Stefik et al., 1987), and distant synchronous communication like teleconferencing facilities; for the access to relevant information and information sources (in particular to those characterizing the decision to be taken and the dynamic context where it is taken); and, finally, for the use of qualitative and quantitative decision- and/or argumentation models (Conklin, Begeman, 1988; Lee, 1990). 
We must mention that the first empirical studies on the effects GDSS use on group work had contradictory results: the quality of decisions, group confidence and satisfaction, the number of comments, the level of conflict are some of the issues on which different studies reported inconsistent observations (Vogel et al., 1988). These studies seem to suggest, if they can suggest anything given their limitations, that the use of the first GDSS has no direct appreciable effect on the group decision process, and that therefore the development of new systems must follow a different orientation. In the late eighties, also in connection with the emergence of the new field of Computer Supported Cooperative Work (CSCW; Ellis et al., 1991; Schmidt, Bannon, 1992) confidence grew relative to the idea that supporting group decision making cannot be separated by supporting its other relevant cooperative activities, like communication and information processing (Kraemer, King, 1986), since group decision making is generally embedded in a more general cooperative process.

New GDSS are therefore expanding the set of services they offer users or embedding them in more general CSCW platforms (Malone, Crowston, 1991).

In this paper I take a slightly different view: both although and because I agree with the mainstream of GDSS research (Kraemer, King, 1986) that group decision processes have a social and processual nature, that communication and information processing activities play an important role in them and, finally that they require systems supporting any form of group work, including but not limited to decision making. I think that decision making as a group cooperative process (let me call it co-decision to distinguish it from individual decision) can and must be analyzed, out of the rationality paradigm lying at the basis of most of the DSS (Keen, Scott-Morton, 1978) and of some of the GDSS (Conklin, Begeman, 1988; Lee, 1990), from a purely pragmatical point of view as a form of cooperation where participants do nothing but take decisions. I also think this analysis can offer new insights on the support it needs and on the support that can be given to it through information and communication technologies.

This paper proposes the approach to cooperative processes under development from more than ten years in Milano (De Michelis, 1994, 1995, 1996) as the theoretical framework where two types of co-decision - respectively, co-decision with equal and with distinct roles - are distinguished and characterized from the viewpoint of positional relations binding their participants within a cooperative process. Afterwards, the requirements which systems supporting the two forms of co-decision must satisfy are briefly discussed and, finally the issues raised by their implementation within an organization are surveyed. An HBR case study (Rothstein, 1995) is recalled in the next section; it is also discussed occasionally in the other sections to give some empirical evidence to the findings they propose.

\section{A CASE HISTORY}

Each issue of the Harvard Business Review (HBR) contains a case study, where various scholars and practitioners of management sciences and related disciplines discuss a case history prepared by one member of the HBR editorial staff. 
In the January-February 1995 issue the HBR case study (Rothstein, 1995) proposes the discussion of the failure of an empowerment project at SportsGear.

The story begins (my rather short summary focuses on the events I consider most relevant) with a board of directors meeting where under the sponsorship of the CEO an empowerment program is launched to revitalize 'SportsGear'; the board also agrees to start it with a project in the manufacturing area. After a seminar where a consultant explains what empowerment is and how it has to be implemented, an empowerment team is created with people from the manufacturing, marketing, IT, and retail departments under the direction of the manufacturing vice-president. They make a commitment to define an empowerment program enhancing the performances of the manufacturing process with respect to customer satisfaction, delivery times, design innovation, information sharing, and so on. The team works together with great enthusiasm for the fixed period and finally comes out with a report proposing some main changes in the manufacturing process: "permit a manager to follow a product from design through sales to customers, allow salespeople to refund up to $\$ 500$ worth of merchandise on the spot, make information available to salespeople about future SportsGear products, swap sales and manufacturing personnel for short periods to provide insights into one another's jobs, and establish a hot line so that salespeople could keep manufacturing informed about how SportsGear products were selling". The story ends with another meeting, where the report is presented to the board of directors but fails to convince all the department directors and is rejected: in particular, the directors of the personnel, financial, legal and strategic planning departments form "a wall of resistance".

The reaction of the board of directors "stunned the team members... they had felt confident in their sound research and thoughtful presentation." They did not expect the story to have this unhappy ending.

The case is well articulated and has many features that can be considered representative of many true change management projects: the CEO has great ideas but does not pay attention to the implementation of his ideas; various department managers show opportunistic behaviour and do not exhibit any opposition to the project until they have the chance to reject it; the empowerment team is enthusiastic but unable to win direct involvement on the part of all the department managers; ....

The comments of the experts (ranging from professors of management sciences and organizational psychology to consultants and top managers) offer various insights and explanations about the factors which caused the failure of the project: all the actors made several tactical errors; empowerment was not grounded on a radical change of the fundamentals of human resource politics; the CEO did not assume responsibility for the project; the empowerment team was not representative and did not involve all the department managers in its activites; the empowerment initiative was not led by the managers but by the consultants.

The comments of the experts are all plausible and meaningful, but they leave me with the impression that they are strongly biased due to the simple fact that they are given after the failure of the empowerment project. This impression is supported by the fact that they are supported by single principles of good change management and not by a theory of organizational decision processes where change management can be taken into account. 
The theory of cooperative processes introduced in the next section offers a coherent language for analyzing the SportsGear case study and discussing its negative outcomes showing that they were generated by the way the decision process was conducted. I will come back to it in the next section.

\section{CO-DECISION FORMS AS COOPERATION FORMS}

As I claimed in the Introduction the decisions taken into consideration in this paper are codecisions, i.e. decisions that are not taken by isolated individuals but are the outcome of a group of persons and are generally part of larger processes, e.g., those processes that are frequently called business (with external focus) and/or organizational (with internal focus). It is well known, in fact, that managerial decisions are generally (co-) decisions of this type, since managers' work has the role of influencing, orienting, controlling the business processes of the organization they manage and of developing organizational processes focused on improving performance. From this point of view, co-decisions have a process nature: they are subprocesses of the process within which they are taken.

This delimitation of the study field opens two complementary research issues: on the one hand, since co-decision is a cooperative subprocess of a larger process, it is necessary to analyze the latter as a cooperative process (it is not important here to distinguish between the two types of processes mentioned above, but to understand their common cooperative nature) and to distinguish the forms cooperation assumes within it (reducing cooperation to a generic and contingent combination of communication and action it is not sufficient, since it does not help in analyzing and evaluating real cooperative processes); on the other, it is necessary to understand the role co-decision plays within cooperative processes and how it is practiced, i.e. to analyze co-decision forms as cooperation forms.

I couple the neutral and general meaning of cooperation to indicate people doing something together (Schmidt, Bannon, 1992) with a relational view on human activities embedding them within the communication flow of its participants (Flores, 1982; Winograd, Flores, 1986). The pragmatic dimension of human communication, in fact, relates the actions of its participants with their expectations, as first, defining the conditions of satisfaction they should meet, as second, declaring if the latter have been met. Every activity, therefore, has at least one client, who has a need and requests its satisfaction, and one performer, who performs to satisfy the request: both the client and the performer contribute to the value of the performed activity, respectively, requesting it and performing it. Human activites have a social nature, they are rooted in the social relations of their participants. They are processes of communication and action, they are cooperative processes.

The primary form of cooperation within a cooperative process is just the collaboration between clients and performers: a cooperative process develops a partnership between them.

Collaboration is performed through the communication between the performers and the clients from which the activity performed by the first ones receives its value. Within collaboration, in fact, perfomers and clients create a common understanding of what has to be 
done, shape the performance under execution and evaluate it. The coupling of a performance and its value within a cooperative process depends on the collaboration of its clients and performers: if it fails this may very easily be because the performers do something that does not satisfy the clients and therefore has no value. Collaboration creates a common language and a common understanding between the clients and the performers through mutual listening. Collaboration is the form of cooperation through which the relationship between clients and performers is carried on successfully. The idea that clients and performers are not competitors but partners and the idea that a project manager is the coach of her team are both captured in the above concept of collaboration.

The plural form for client(s) and performer(s) above is not casual: cooperative processes have, generally, more than one performer (only trivial activities can be performed by one unique actor; in all the other cases several performers cooperate to perform them) and, frequently, more than one client (in an organizational structure, as an example, a requested performance impacts several persons, who all are, sometimes without knowing it, its clients). A cooperative process can be represented in graphical form as in Figure 1.

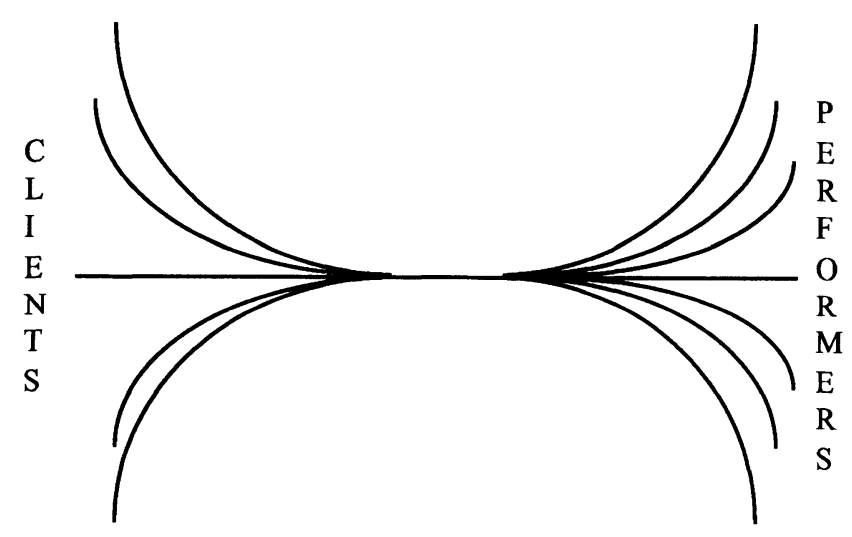

Figure 1 A cooperative process as a relation between clients and performers.

In the HBR case study (Rothstein, 1995) recalled in section 2 several actors participate to the organizational process that should lead to the empowerment of SportsGear: the CEO; the members of the empowerment team, including the manufacturing vice-president and people from the manufacturing, IT, marketing and retail departments; the external consultant; the directors of all the other departments (personnel, financial, legal and strategic planning). The positions they occupy with respect to the performance of the process (designing and implementing an empowerment program) are well defined for the CEO (he is a client), the 
empowerment team and the external consultant (they are all performers) while those of the department directors exhibit a serious ambiguity, that is a relevant indicator of a major problem in process. It is possible to give two different interpretations of the above mentioned ambiguity:

1. they are clients, since, as members of the board, they are the requestors of the empowerment program to the team led by the manufacturing vice-president. The bitter surprise of the empowerment team during the final meeting is therefore generated by its wrong expectation that they would act as performers. The CEO has also some responsibility on the failure of the program because he did not play adequately his role of primus inter pares among the clients;

2. they are performers, since the CEO is their client with respect to the plans discussed at the meetings of the board of directors. This is frequently the case in today enterprises, where managerial meetings are organized to operationalize strategic plans transforming them into departmental action plans. In this case the failure of the empowerment program is due to the lack of responsibility assumption by the directors of the personnel, financial, legal and strategic planning departments. During the final meeting they act as clients, while they are performers.

As it has been claimed above, the collaboration between clients and performers is the main form of cooperation within a cooperative process. But it is not the only one, when the process is not a trivial one. The coordination of the performances of the many performers of a complex cooperative process so that they can result in the satisfaction of the request of its clients, as well as the harmonization of the conditions of satisfaction of its many clients are performed through different cooperation forms, deserving a particular attention.

On the one hand, the activities of the performers are interrelated in a partial order of causal dependencies, characterizing the flow of actions that conducts to the completion of the cooperative process. Disregarding the normative means (procedures, roles, plans, ...) through which this partial order is defined and maintained, whose analysis is out of the scope of this paper (De Michelis, 1996), it can be observed that any activity in the partial order is embedded by its causal dependencies within a cooperative (sub-) process, whose clients include some of the performers of the main process themselves. Every performer of a cooperative process is generally, also, client within some of its sub-processes. A similar observation can be made also with respect to its clients, that sometimes are performers of some of its sub-processes. Within a cooperative process, every participant switches from one position to another one (e. g. from performer to client) collaborating in different moments with a different sub-group of participants.

On the other hand, between the many clients of a cooperative process there is a mutual relation that is not a client - performer collaboration, but it is based on their being all clients within the same cooperative process. The client - client relation is not associated with a cooperative sub-process, it does not embed any activity: it is a purely communicative relation, developing in time, where the clients harmonize their conditions of satisfactions and agree on one common unique request to be satisfied, i.e they co-decide it. All the clients are equal with respect to the request they co-decide: every one of them, in fact, has a condition of 
satisfaction that must be met by the unique performance of the cooperative process. They play equal roles within the co-decision.

Co-decision with equal roles occurs when two or more people participate in a decision process where all of them share full responsibility for the decision to be taken. Co-decision with equal roles is a process where the opinions of all the participants converge towards a common decision. Convergence may be enhanced either through persuasion or through mediation. Co-decision with equal roles, logically precedes the action: if it is carried on successfully, it fixes the common expectations with respect to the outcome of a cooperative process; it defines the condition of satisfaction shared by all its clients. Co-decision with equal roles is carried on by the clients of a cooperative process. If a cooperative process has several clients, each can be considered as intermediating a different relationship with the environment in which the cooperative process is performed: the cooperative process has a complex relationship with its environment; it has a complex environment. Co-decision with equal roles is the means through which the cooperative process is protected from the complexity of its environment.

Finally, between the many performers of a cooperative process there is, also, a mutual relation that is not a client - performer collaboration, but it is based on their being all performers within the same cooperative process. The performer - performer relation is not associated with a cooperative sub-process, it does not embed any activity: it is a purely communicative relation, developing in time, where the performers maintain the coupling between their performances, so that their integration is possible and effective. Also in this case, the participants are involved in a co-decision process, but the latter has a rather different nature with respect to co-decision with equal roles. Every performer, in fact, has only responsibility on her performance and on its fitting with the performances of the other performers; every one of them has a different responsibility in the decision to be taken. The performers play different roles in the co-decision.

Co-decision with distinct roles occurs when two or more persons participate in a decision process, where each has her own responsibility on a particular issue related to the whole decision to be taken. Co-decision with distinct roles is a process where the individual decision of any participant takes into account the constraints defined by the decisions of the other participants, so that overall the individual decisions constitute a sound collective decision. Successful co-decision with distinct roles creates a non void intersection among the decisions the participants take on the issues under their responsibility. Through successful co-decision with distinct roles the participants in a cooperative process recognize and maintain the mutual interfaces between their respective performances. Co-decision with distinct roles is carried on by persons which are all performers of the same activity.

From this short summary of the three main cooperation forms (more can be found in: De Michelis, 1994) many aspects of co-decision emerge deserving a closer attention in order to analyze the requirements the systems supporting co-decision should meet.

'Client' and 'performer' do not define roles, rather they define relative positions: a participant in a cooperative process is neither a client nor a performer. At any moment, she is in a client or performer position depending on the activity she is currently engaged in and on her responsibility on it. At any moment, she is in a client (performer) position in one specific 
(sub-) process where other persons (not necessarily all the participants of the cooperative process) are involved either in client or in performer positions. Whenever she switches from one activity to another one she changes her position accordingly. Positions are relative because they are context dependent: they depend on the past history of the cooperative process, on the partial order of causal dependencies of its action flow, on its participants, on their mutual positions, on its communication flow. The way people cooperate within a cooperative process is also highly context dependent: to perform effectively a person must know not only what is her task but also where she is situated (Suchman, 1987).

The participants in a cooperative process, from this viewpoint, are members of a social community, of a community of practice (Seely Brown, Duguid, 1991): the concept of position is not superposing to it any formal organization but offers a means to analyze the complexity of its cooperative processes and how it impacts their performances (De Michelis, 1994, 1995, 1996).

Cooperation forms are strictly coupled with positional relations: collaboration occurs between clients and performers; co-decision with equal roles between clients; co-decision with distinct roles between performers. A form of cooperation is not a style of behaviour a person can choose: it is a matter of practicing a social relation. A person can not choose the form of cooperation she engages herself in, nor a group of persons can do it: the form of cooperation they engage in depends on the positional relations where they are situated.

Moreover, whenever a group of persons is engaged in a particular cooperation form, then they are in the correspondent positional relationship: if they are collaborating, then they are in a client - performer relationship; if they are co-deciding with equal or distinct roles, then they are, respectively, in a client - client or performer - performer relationship. From the way people are cooperating the observer can induce some information about the cooperative process to which they participate. Since cooperation occurs only within cooperative processes, group decision making is always part of a cooperative process.

There are two rather different forms of co-decision where participants interact in rather different ways: a behaviour which is effective in one of them is not effective in the other. Both the rational decision approach and the managerial common sense (the former has deeply influenced the latter) have paid a great attention to one of them - co-decision with equal roles disregarding the other one. GDSS are either supporting synchronous communication, like decision rooms and collaboration laboratories, or supporting co-decision with equal roles (Conklin, Begeman, 1988; Lee, 1990). Only in the software engineering field some tools have been designed taking into account co-decision with distinct roles and the problem of the consistency of the interfaces between concurrent activities.

The pragmatical approach presented here allows to make one step further with respect to the garbage can model of group decision making (Kraemer, King, 1986), enriching its capability of taking into account the diversity decision processes may exhibit, with some insights in the forms of their diversity.

In the HBR case study presented in section 2 (Rothstein, 1995), the 'wall of resistance' of the directors of the personnel, financial, legal and strategic planning departments shows without any doubt that they are behaving in accordance with co-decision with equal roles: they reject the program with highly general remarks, underlining the dangers to which it 
exposes SportsGear rather than the problems they think their departments will individually encounter if it is implemented.

From the rational decision viewpoint the ambiguity of their position is not relevant: the only interesting evaluation is if they are right rejecting the empowerment program prepared by the team or not. It is only from the pragmatic point of view that emerges the question of their position with respect to the empowerment plan and it makes sense asking if their cooperation has been coherent with their responsibility. What can be evaluated in terms of rationality from one viewpoint is characterized in terms of responsibility from the other.

\section{COMPUTER SUPPORT FOR CO-DECISION}

As it has been recalled in the Introduction of this paper, there is a substantial agreement today that systems supporting group decision making can not be effective if they are not supporting also any other cooperative activity of its actors. The analysis carried on in the previous section allows to go further in the characterization of the requirements they must satisfy, avoiding the generic call for systems supporting any form of communication, cooperation and information processing.

In the previous section it has been shown that human beings are situated in the cooperative process in which they currently participate and, furthermore, that at any moment their situatedness is characterized by their positions in it and by their mutual positional relations.

The complexity of cooperative processes makes particularly difficult for participants remaining aware of the context where they are situated. On the one hand, they have difficulties to understand what is going on, what they should do, how they should behave, what the other participants are doing and should do, and the resolution of these doubts to move to action becomes time and resource consuming affecting their performances and stressing them; on the other, sometimes they feel that they didn't do the right thing, or that someone else didn't do it, causing problems, again, that have negative effects on the cooperative process, i.e. affecting their performances and stressing them.

In both cases, the problems are generated by a lack of awareness of the context where they are situated. Systems supporting the actors of a cooperative process, while they are codeciding or, more generally, while they are engaged in any form of cooperation, should therefore enhance their awareness of the context where they are situated, taking into account of the different dimensions of that context.

First, they should enhance user awareness of the cooperative process where she is situated. Remaining in the spatial metaphor a cooperative process is performed in a work setting with a physical and an electronic component. While the former is characterized by the arrangements of the work space where its participants are located, the electronic component of the work setting is its virtual augmentation generated by the interface allowing the access to computerbased tools and systems: productivity tools, information repositories and, mainly, communication media. The quality of a system supporting cooperative processes depends, therefore, both on the richness of the tool set it offers to its users and on the way its interface makes them available in their work setting. Its interface must reflect the ongoing cooperative 
process offering services to the cooperation form its participants are engaged in, so that they can access transparently or in a visible way (Agostini et al., 1996) the tools allowing her to cooperate appropriately.

The groupware platforms already available in the market offer some services from this point of view, while new more powerful prototypes are currently under development: the BSCW system at GMD (Bentley et al., 1995) and the Milano system at the Cooperation Technologies Laboratory of the University of Milano (Agostini et al., 1995, 1996b). The Milano system couples the work center concept of Anatol Holt (Holt et al., 1983; Holt, 1988 ) with the relational view of cooperative processes proposed in this paper, so that its user interface mirrors the cooperative process where its user is situated in her work space.

Second, they should enhance user awareness of the positional relation binding her with the persons with whom she is cooperating and of the cooperation form associated to it. The question here is to support the awareness of a user not only with respect to the cooperative process where she is situated but also with respect to its sub-process where she is currently active. The user interface of the system should, therefore, at any moment make available to its user the tools that are needed in the form of cooperation and/or in the activity in which she is engaged. Moreover, when the user moves from one cooperation form to another one, the system should switch accordingly. The Milano system offers some hints on how this level of awareness can be supported (Agostini et al., 1995, 1996b).

Third, they should enhance user awareness of the cooperative form where she is currently acting, with a particular attention to co-decision forms. Let us have a closer look at the type of support we can envision for the two forms of co-decision.

- Whenever a cooperative process has more than one single client, then co-decision with equal roles is the cooperation form through which the clients share their expectations with respect to the process outcome, so that the performers know what they have to do. The main co-decision problem is generated by the fact that those, who should take a decision together, do not cooperate properly during the process. If, when a breakdown occurs, each of the clients reactivate the collaboration with the performers without taking into account the opinions of all the other clients, the performers can not understand which are the conditions of satisfaction of their performance, and the cooperative process can fail to reach a successful completion. Making expectations visible, helping the participants to understand each other and allowing to change expectations, within the space of possibilities of the performer is what supporting systems should do with respect to co-decision with equal roles. Systems like $\mathrm{CM} / 1^{\mathrm{TM}}$, the industrial derivation of gIBIS (Conklin, Begeman, 1988), are particularly well suited to support co-decision with equal roles.

- Whenever a cooperative process has several performers who concurrently act to satisfy the same client, co-decision with distinct roles is the cooperation form through which the performers maintain the integration conditions of their respective performances. If they are able to define together the interfaces mutually constraining their respective performances, then their performances will be able to meet the condition of satisfaction of their common clients. As with co-decision with equal roles, also co-decision with distinct roles may become critical, because those, who should take a decision together, do not cooperate properly during the process. If, when a breakdown occurs, each of them looks for the best 
general solution able to fit the condition of satisfaction of the client, instead of looking to the changes she can afford in her specific task, redefining its interfaces with the tasks of the other performers, then the cooperative process can enter in crisis, as its participants relinquish their own responsibilities of performers to play mutually as clients. Co-decision with distinct roles is, generally, badly understood and badly supported within cooperative processes. For particular types of activity - e.g. software engineering - the methods and tools used to guide the development process embody a discipline for the definition and maintainance of the interfaces between subtasks, but no general tools have been designed to support co-decision with distinct roles.

The three types of awareness are presented in order of relevance, since a person can not be aware of the form of cooperation she is practicing if she is not aware of the cooperative process wher she is engaged and she can not be capable to co-decide properly without being aware of the position she occupies.

The problem, therefore, is not to switch from GDSS to more general groupware systems supporting any form of cooperation, but to embed GDSS in a groupware platform supporting user awareness and open to modularity (Agostini et al., 1996). GDSS, in fact, like any other cooperative and/or individual tool, are resources for action (Suchman, 1987) that the user needs within the context where she is situated.

\section{IMPLEMENTING CO-DECISION SUPPORT}

The implementation of a co-decision support system within an organization is not a technical matter: it is a complex change management process impacting all the dimension of the sociotechnical system characterizing that organization. The quality of the system is not a sufficient condition for granting its success.

In the following some major aspects of the above claim are briefly recalled.

Before implementing a co-decision support system it is necessary to foresee the performances it should improve within the organization, so that every involved person can understand its importance. From this point of view, the rational decision approach is often misleading, since it focus on the abstract dimension of the optimality of the decisions to be taken, rather than on the performances of the processes where they are taken. Decision making, generally, is not important per se, out of the context where it occurs.

When implementing a co-decision support system it is also necessary to analyze carefully the current practices of the involved persons. A realistic look at them will help to avoid technological innovations that are not usable in the context of the organization where the implementation will take place. Real case studies show, for example, that paper is still in many cases the most acceptable document support for managers involved in decision making. One important guideline is therefore to implement the new system in such a way that it supports in an integrated way both paper and electronic wok.

Like any change management process, the implementation of a co-decision support system impacts dramatically its users. A particular attention must be paid to their empowerment so 
that the users can fully exploit the services offered by the new system while improving their performances. Moreover, the implementation itself must be conceived as part of this empowerment program. The effective use of co-decision support systems is, in fact, impossible if its users do not abandon the rational decision common sense to share the new pragmatic viewpoint characterizing decision making in terms of responsibility.

Improving group decision making within an organization is not possible if organizational roles and structures remain unchanged, since co-decision forms can be obstacled by organizational rules. Implementing a co-decision support system must either be an occasion for a global rethinking of the organization or, at least, be accompanied by those organizational changes that are necessary for the full exploitation of the system to be implemented.

Finally, the implementation of a co-decision support system is not instantaneous: it is a cooperative process (an organizational process, in accordance with the definitions given in this paper). As such, it needs to be supported by cooperative process support systems and by co-decision support systems.

\section{CONCLUSION}

The pragmatic approach to cooperative processes within which co-decision with equal and with distinct roles have been distinguished, constitutes the conceptual basis of the prototype of the Milano system for supporting cooperative processes, under development at the Cooperation Technologies Laboratory of the University of Milano (Agostini et al., 1995, 1996b).

The characterization of the two co-decision forms proposed in this paper will be tested and improved, so that it can offer the guidelines for the specification and the design of the codecision support modules of the Milano system.

\section{ACKNOWLEDGMENTS}

I thank Alessandra Agostini and Maria Antonietta Grasso for the many discussions we had about the issues raised in this paper and Monica Divitini for her careful reading and correcting it. This paper presents a research that has been conducted with the financial support of the EC within the IMPACT project of the COST-14 Action, and of the Italian National Research Council (CNR) within the coordinated project "Environments for Supporting the Design of Information System". 


\section{REFERENCES}

Agostini, A., De Michelis, G. and Grasso M. A. (1995). The Milano System, in A Computational Model of Organizational Context, COMIC Deliverable 1.3, 163-92 (Available on request from the Computing Department, University of Lancaster, Lancaster LA1 4YR, UK, e-mail: tom@comp.lancs.ac.uk).

Agostini, A., De Michelis, G., Grasso, M. A., Prinz, W. and Syri, A. (1996) Contexts, Work Processes and Workspaces. Computer Supported Cooperative Work (CSCW). An International Journal, (to appear).

Agostini, A., De Michelis, G. and Grasso M. A. (1996b) Cooperative processes in the net. Technical Report CTL-DSI Milano University, Milano.

Bentley, R., Horstmann, T., Sikkel, K. and Trevor J. (1995): Supporting Collaborative Information Sharing with the World Wide Web: The BSCW Shared Workspace System, in Proceedings of the 4th WWW Conference, Boston.

Conklin, E. J. and Begeman, M. L. (1988) gIBIS: a hypertext tooling for exploratory policy disucssion, in Proceedings of the 2nd Computer Supported Cooperative Work Conference 1988, ACM, New York, 140-52.

De Michelis, G. (1994) From the analysis of cooperation within work-processes to the design of CSCW Systems, in Proceedings of the 15th Interdisciplinary Workshop on Informatics and Psychology: Interdisciplinary approaches to system analysis and design, Schaerding, May 24 - 26.

De Michelis, G. (1995) Computer Support for Cooperative Work: Computers between Users and Social Complexity, in Organizational Learning and Technological Change (eds. C. Zucchermaglio, S. Bagnara and S. Stucky), Springer Verlag, Berlin, 337-330.

De Michelis, G. (1996) Work Processes, Organizational Structures and Cooperation Supports: Managing Complexity, in Proceedings of the 5th IFAC Symposium on Automated systems Based on Human Skills - Joint Design of Technology and Organization. Elsevier International, Oxford, (to appear).

De Michelis, G. and Grasso, M. A. (1994) Situating conversations within the language/action perspective: the Milan Conversation Model, in Proceedings of the 5th Computer Supported Cooperative Work Conference 1994, ACM, New York, 89-100.

Dennis, A. R., Joey, F. G., Jessup, L. M., Nunamaker, J. F. and Vogel, D. R. (1988) Information technology to support electronic meetings. MIS Quarterly, 12.4, 591-619.

Ellis, C. E., Gibbs, S. J. and Rein, G. L. (1991) Groupware: some issues and experiences, Communications of the ACM, 34.1, 38-57.

Flores, F. (1982) Management and Communication in the Office of the Future, Hermenet San Francisco.

Holt, A. W. (1988) Diplans: A New Language for the Study and Implementantion of Coordination. ACM Transactions on Office Information Systems, 6.2, 109-25.

Holt, A. W., Ramsey, H. R. and Grimes, J. D. (1983) Coordination System Technology as the basis for a programming environment. Electrical Communication, 57.4, 307-14.

Lee, J. (1990) Sibyl: a tool for managing group decision rationale, in Proceedings of the 3rd Computer Supported Cooperative Work Conference 1990, ACM, New York, . 
Lee, R. M., McCosh, A. M. and Migliarese P. (1988) Organizational decision support systems. North Holland, Amsterdam.

Keen P. G. W. and Scott-Morton M. S. (1978) Decision support systems. Addison-Welsey, Reading.

Kraemer, K. and King, J. L. (1988) Computer-based systems for cooperative work and group decision making. ACM Computing Surveys, 20.2, 115-46.

Malone, T. W. and Crowston, K. (1991) Towards an interdisciplinary theory of coordination (TR\#120), Centre for Coordination Science, M.I.T., Cambridge.

Rothstein, L. R. (1995) HBR Case Study. The Empowerment Effort that Came Undone. Harvard Business Review, 73.1, 20-31.

Schmidt, K. and Bannon L. (1992) Taking CSCW Seriously: Supporting Articulation Work. Computer Supported Cooperative Work. An International Journal, 1.1/2, 7-40.

Seely Brown, J. and Duguid, P. (1991) Organizational Learning and Communities of Practice: a unified View of Working, Learning and Innovation. Organization Science, 2.1, 40-56.

Simon, H. (1960) The New Science of Management Decision. Harper \& Row, New York.

Sprague, R. H. and Carlson, E..D. (1982) Building effective decision support systems. PrenticeHall, Englewood Cliffs.

Stefik, M., Foster, G., Bobrow, D. G., Kahn, K., Lanning, S. and Suchman, L. (1987) Beyond the chalkboard: computer support for collaboration and problem solving in meetings. Communications of the ACM, 30.1, 32-47.

Suchman, L. A. (1987) Plans and Situated Actions. Cambridge University Press, New York.

Vogel, D. R., Nunamaker Jr., J. F., George, J. F. and Dennis, A. R. (1988) Group decision support systems: evolution and status at the University of Arizona, in Organizational decision support systems (eds. R. M. Lee, A. M. McCosh and P. Migliarese). North Holland, Amsterdam, 287-304.

Winograd, T. and Flores, F. (1986) Understanding Computers and Cognition. Ablex, Norwood.

\section{BIOGRAPHY}

Giorgio De Michelis teaches Theoretical Computer Science at the University of Milano, where he has been working since 1972 .

His research covers the models of concurrent systems (Petri Nets) and Computer Supported Cooperative Work, where he has developed and is developing prototypes of support systems for cooperative processes (CHAOS, UTUCS, MILANO).

$\mathrm{He}$ is responsible of the Cooperation Technologies Laboratory at the Dipartimento di Scienze dell'Informazione of the University of Milano; he is Chairman of the Management Committee of the European Community COST 14 Action, CO-TECH.

$\mathrm{He}$ is author of more than eighty papers in the areas of his interest. 